\title{
Physiological analysis to quantify training load in badminton
}

\author{
P Majumdar, G L Khanna, V Malik, S Sachdeva, Md Arif, M Mandal
}

\begin{abstract}
Objective-To estimate the training load of specific on court training regimens based on the magnitude of variation of heart rate-lactate response during specific training and to determine the magnitude of variation of biochemical parameters (urea, uric acid, and creatine phosphokinase (CPK)) 12 hours after the specific training programme so as to assess training stress.

Methods-The study was conducted on six national male badminton players. Maximum oxygen consumption $\left(\dot{V}_{2}\right)$, ventilation $\left(\dot{V}_{\mathrm{E}}\right)$, heart rate, and respiratory quotient were measured by a protocol of graded treadmill exercise. Twelve training sessions and 35 singles matches were analysed. Heart rate and blood lactate were monitored during technical training routines and match play. Fasting blood samples collected on two occasions-that is, during off season and 12 hours after specific training-were analysed for serum urea, uric acid, and CPK.
\end{abstract}

Results-Analysis of the on court training regimens showed lactate values of 8-10.5 $\mathrm{mmol} / \mathrm{l}$ in different phases. The percentage of maximum heart rate ranged from $82 \%$ to $100 \%$. Urea, uric acid, and CPK activity showed significant changes from (mean (SD)) $4.93(0.75) \mathrm{mmol} / \mathrm{l}$ to 5.49 (0.84) $\mathrm{mmol} / 1,0.23(0.04)$ to $0.33(0.06)$ $\mathrm{mmol} / \mathrm{l}$, and $312(211.8)$ to 363 (216.4) IU/1 respectively.

Conclusion-Maximum lactate reported in the literature ranges from $3-6 \mathrm{mmol} / 1$. Comparatively high lactate values and high percentage of maximum heart rate found in on court training show a considerable stress on muscular and cardiovascular system. The training load needs appropriate monitoring to avoid overtraining. Workouts that are too intensive may interfere with coordination, a factor that is important in sports requiring highly technical skill such as badminton. (Br F Sports Med 1997;31:342-345)

Keywords: badminton; creatine phosphokinase; lactate; heart rate monitoring

Unlike other sports, the physical and physiological profiles of badminton players are scarce in the literature. ${ }^{1-8}$ The demand of sports has been analysed and it has been reported that training games in elite badminton performers are predominantly aerobic activity, while a few sporadic attempts have been made to assess the effect of a general training programme designed for badminton players. ${ }^{78}$ The consensus on fitness development is that, badminton players should incorporate flexibility, strength, and endurance training in their programmes to reduce fatigue and muscular injuries, while simultaneously improving performance. Specific training routines have been developed and monitored, however, which are sufficiently intense to cause an increase in blood lactate concentration. ${ }^{7}$ This type of training is probably especially beneficial for competition play where a greater reliance on anaerobic glycolysis may be expected to sustain work over rallies and games of longer duration. ${ }^{7}$ This study was undertaken to consider the following aims and objectives. (1) To assess the heart rate and lactate responses during actual play to quantify the energy demand of the game. (2) To examine the physiological responses in an on court technical training regimen, to measure the comparative assessment of training load and physiological stress of match play. (3) To find out the magnitude of variation of biochemical parameters (urea, uric acid, creatine phosphokinase $(\mathrm{CPK})$ ) after the specific training programme compared with off season resting values, to assess training stress.

\section{Methods}

This study was conducted on six national male badminton players attending a training camp at the Sports Authority of India. Oxygen consumption $\left(\dot{\mathrm{V}}_{2}\right)$, carbon dioxide production $\left(\dot{\mathrm{V}} \mathrm{CO}_{2}\right)$, ventilation $\left(\dot{\mathrm{V}}_{\mathrm{E}}\right)$, heart rate were measured during graded treadmill exercise (Jaeger, Germany). The initial speed of the treadmill was $8 \mathrm{~km} / \mathrm{h}$ with an inclination of $2 \%$ and thereafter the speed was increased by $2 \mathrm{~km} / \mathrm{h}$ after every two minutes until a plateau of $\dot{\mathrm{VO}}_{2}$ was attained or the respiratory quotient $(R Q)$ value exceeded 1.15. The whole experiment was performed at room temperature varying from $23-25^{\circ} \mathrm{C}$ with the relative humidity varying between $50-60 \% .^{9}$ Regression equation of $\dot{\mathrm{V}}_{2}-\mathrm{HR}$ was calculated to estimate indirectly the oxygen consumption from heart rate. ${ }^{10}$

MONITORING OF A SINGLES GAME

The heart rate of each player was measured continuously at five second intervals during a singles game in competitive match play by a telemetry (sports tester PE-3000). The data stored in the memory of the watch were then downloaded to a computer and evaluated using proprietary software (Polar Electro, Finland). After each game, arterialised capillary blood 
Table 1 Training programmes adopted for speed endurance

\begin{tabular}{llllllll}
\hline Training & $\begin{array}{l}\text { Duration of } \\
\text { activity }(\mathrm{s})\end{array}$ & $\begin{array}{l}\text { Intensity HR } \\
\text { (beat/min) }\end{array}$ & $\begin{array}{l}\text { Number of } \\
\text { repetitions in set }\end{array}$ & $\begin{array}{l}\text { Duration of } \\
\text { rest between } \\
\text { repetitions }(\mathrm{s})\end{array}$ & $\begin{array}{l}\text { Recovery HR in } \\
\text { between rest } \\
\text { (beat/min) }\end{array}$ & $\begin{array}{l}\text { Rest between } \\
\text { sets (min) }\end{array}$ & $\begin{array}{l}\text { Recovery HR } \\
\text { (beat/min) }\end{array}$ \\
\hline Shadow & $40-50$ & $153-190$ & $6-8$ & $40-50$ & $150-165$ & 2 & $105-130$ \\
Multishuttle & $40-50$ & $165-185$ & $3-4$ & $60-120$ & $130-173$ & 5 & $104-170$ \\
\hline
\end{tabular}

Table 2 Descriptive data for subjects ( $n=6$ )

\begin{tabular}{|c|c|c|}
\hline Age $(y)$ & 24.3 & (4.1) \\
\hline Height $(\mathrm{cm})$ & 175.4 & $(5.4)$ \\
\hline Weight (kg) & 64.8 & $(6.9)$ \\
\hline Body fat (\%) & 12.1 & (3.4) \\
\hline$\dot{\mathrm{V}} \mathrm{O}_{2} \max (1 / \mathrm{min})$ & 3.57 & $7(0.45)$ \\
\hline$\dot{\mathrm{V}} \mathrm{O}_{2} \max (\mathrm{ml} / \mathrm{kg} / \mathrm{min})$ & 55.7 & $(4.4)$ \\
\hline Maximum heart rate (beat $/ \mathrm{min}$ ) & 183 & (6) \\
\hline
\end{tabular}

Data shown as mean (SD).

samples were drawn from a finger tip, between two and three minutes after the cessation of the activity. ${ }^{11}$ The samples were analysed in a calibrated automatic lactate analyser (Analox Instruments Ltd, UK) for estimating whole blood lactate. A total of 15 matches were analysed, of which 10 comprised two games, while the remaining five matches extended to three games. In total, 35 games were analysed, involving six players, and $\dot{\mathrm{V}}_{2}$ was predicted from the regression equation. The heart rate and $\dot{\mathrm{V}}_{2}$ were measured over a range of exercise intensities using the treadmill, and the $\mathrm{HR}-\dot{\mathrm{VO}}_{2}$ relation established. ${ }^{12}$ Telemetred heart rate values during actual game were obtained and their corresponding $\mathrm{Vo}_{2}$ used to estimate the oxygen uptake during play. The high correlation coefficients ordinarily obtained between $\mathrm{HR}-\dot{\mathrm{VO}}_{2}{ }^{1314}$ support the use of the $\mathrm{HR}-\mathrm{VO}_{2}$ relation for estimating game $\mathrm{V}_{2}$.

\section{MONITORING THE TRAINING PROGRAMME}

Specific on court programmes were given to improve speed endurance. Table 1 gives the details of the programmes. On court technical training consisted of five segments in which the different intensity of effort was imposed by manipulating work-rest ratio. These routines were three sets of "shadow play" and two sets of "multishuttle" work. Total work over 80 minutes was undertaken with a work-rest interval ratio of $1: 1$ in "shadow play" but in "multishuttle" the duration of activity: rest was 40-50 seconds : $60-120$ seconds with repetitions varying from six to eight in each segment.

Table 3 Physiological parameters during match play (men)

Mean (work):(rest)

Mean $\mathrm{VO}_{2}(1 / \mathrm{min})$

Per cent of $\dot{\mathrm{VO}}_{2}$ max

Average heart rate (beat $/ \mathrm{min}$ )

Maximum heart rate (beat $/ \mathrm{min}$ )

(4.6 (1.5)):(9.7 (2.4))

Lactate $(\mathrm{mmol} / \mathrm{l})$

$2.29(0.58)$

$57.10(24.50)$

$157.00(11.00)$

$183.00(9.00)$

$4.70(1.90)$

Data shown as mean (SD)

Table 4 Specific on court training in badminton $(n=6)$

\begin{tabular}{lccccc}
\hline & $S g 1$ & $S g 2$ & $S g 3$ & $S g 4$ & $S g 5$ \\
\hline Time (min) & $12: 0$ & $9: 0$ & $12: 0$ & $6: 0$ & $10: 0$ \\
Lactate (mmol/l) & $8(3)$ & $9.3(2.9)$ & $10.5(3.1)$ & $10.4(2.5)$ & $8.7(1.4)$ \\
Average heart rate (beat/min) & $157(3)$ & $167(4)$ & $175(4)$ & $172 \quad(4)$ & $153 \quad(8)$
\end{tabular}

Lactate $=$ NS. Average heart rate: ${ }^{\star}$ Sg $1 v \operatorname{Sg} 2{ }^{\star \star}{ }^{\star} \operatorname{Sg} 1 v \operatorname{Sg} 3,{ }^{\star \star} \operatorname{Sg} 1 v \operatorname{Sg} 4,{ }^{\star \star} \operatorname{Sg} 2 v \operatorname{Sg} 5$,

$\star \star \mathrm{Sg} 3 v \mathrm{Sg} 5,{ }^{\star} \mathrm{Sg} 4 v \mathrm{Sg} 5$. ${ }^{\star \star} \mathrm{P}<0.01$. Data shown as mean (SD).
Three training sessions of each badminton player, and a total of 15 training sessions were monitored. Lactate measurements were made after the sets in each segment. Heart rate response was monitored by Sportstester-PE3000 , and blood samples for lactate analysis were drawn immediately after each workout of shadow play and multishuttle activity. ${ }^{15} 16$

BIOCHEMICAL ANALYSIS

Blood samples were taken from the antecubital vein by venipuncture. The samples were taken on the first day of the camp and 12 hours after each specific on court training session. Haemoglobin, urea, uric acid, and CPK were analysed by HITACHI UV-2000 spectrophotometer, using Boehringer Mannheim reagents.

\section{STATISTICAL ANALYSIS}

To establish the difference in specific on court training (lactate and average heart rate), one way analysis of variance was applied followed by Schaffe's post-hoc analysis .

To establish significance in the biochemical variables in "day to day training" and "off season values" a paired $t$ test was applied. ${ }^{17}$

\section{Results}

Table 2 gives the descriptive data for the subjects. Table 3 gives the data obtained during match play. The mean (SD) duration of rallies was 4.6 (1.5) seconds with a mean (SD) rest of 9.7 (2.4) seconds. The mean (SD) $\mathrm{Vo}_{2}$ was 2.29 $1 / \mathrm{min}$, that is $57 \%$ of $\dot{\mathrm{V}}_{2}$ maximum. Peak heart rate was 183 (9) beat $/ \mathrm{min}$ and average heart rate was 157 (11) beat $/ \mathrm{min}$. Mean (SD) blood lactate during match play was 4.7 (1.9) $\mathrm{mmol} / \mathrm{l}$.

Analysis of on court training revealed that mean (SD) lactate values increased from the first to the third segment $(8.0$ (3.0) to 10.5 (2.5) $\mathrm{mmol} / \mathrm{l}$ ) in "shadow play". In "multishuttle" the blood lactate decreased in the fifth segment (8.7 (1.4) $\mathrm{mmol} / \mathrm{l}$ ) (table 4, fig 1). Mean (SD) heart rates of the five segments were 157 (3), 167 (4), 175 (4), 172 (4), and 153 (8) beat/min respectively. Mean heart rate peaked in the third segment, after which it decreased to the fifth segment. Peak lactate was found in the third segment. The duration of the third segment was 12 minutes, with a mean heart rate of 175 (4) beat $/ \mathrm{min}$. Average heart rates in training were significantly lower $(p<0.01)$ in segment 1 and segment 5 compared with other segments. Lactate, however, did not show any significant difference when compared with other segments. However, the percentage increment between segment 1 and segment 2 was $16 \%$, and in segment 3 it further increased by $12 \%$. In segment 5 lactate concentration was reduced by $19 \%$ from 10.4 to $8.7 \mathrm{mmol} / \mathrm{l}$ when compared with segment 4 . 


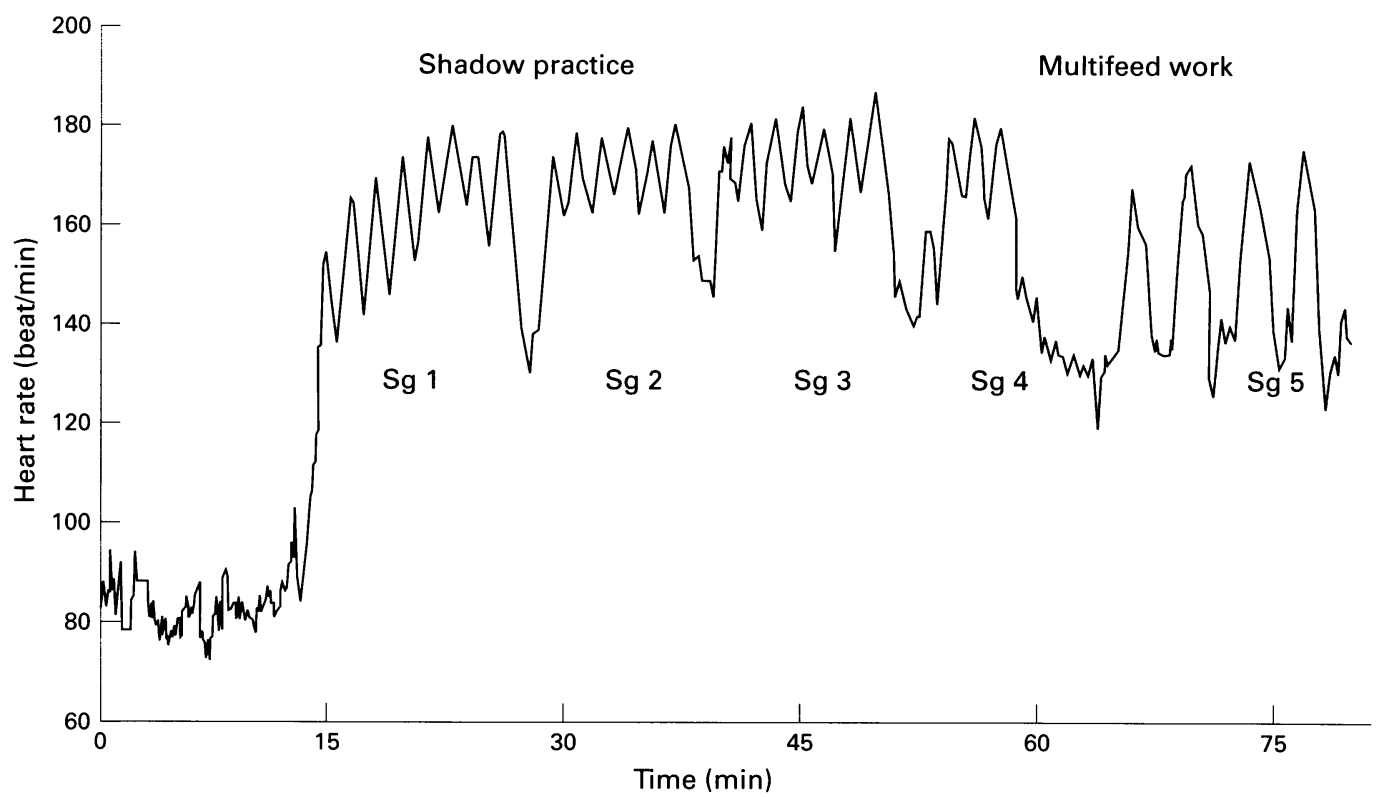

Figure 1 Example of heart rate response in on court technical training.

Table 5 Changes in biochemical variables in on court training

\begin{tabular}{|c|c|c|c|}
\hline & Before & After & \\
\hline Haemoglobin (g\%) & $15.47(0.80)$ & $15.75(0.91) \mathrm{N}$ & NS \\
\hline Urea $(\mathrm{mg} \%)$ & $29.50(4.56)$ & $32.90(5.03)$ & * \\
\hline Uric acid (mg\%) & $3.90(0.66)$ & $5.86(0.96)$ & $\star \star$ \\
\hline CPK (IU/l) & $312.00(211.8)$ & $363.40(216.2)$ & $\star \star$ \\
\hline
\end{tabular}

Table 5 shows the effect of regular monitoring of training on biochemical variables. It shows that urea has increased significantly from $4.93(0.75) \mathrm{mmol} / 1$ to $5.49(0.84) \mathrm{mmol} / 1$ $(\mathrm{p}<0.05)$. Uric acid concentration increased from $0.23(0.04)$ to $0.33(0.06) \quad \mathrm{mmol} / 1$ $(\mathrm{p}<0.01)$. CPK also showed a significant $(\mathrm{p}<0.01)$ increment from $312(211.8)$ to 363 (216.4) IU/1. The percentage increments of after training over before training values were $11 \%, 50 \%$, and $16 \%$ for urea, uric acid, and CPK respectively. No significant changes were observed in haemoglobin, which in part shows there was comparatively little change in haemoglobulin concentration.

\section{Discussion}

Docherty ${ }^{18}$ reported mean (SD) durations of 4.9 (1.3), $4.2(0.5)$, and $4.9(0.7)$ seconds per rally for badminton players of low, medium, and high skill levels, respectively. The figures from Danish recreational badminton are also similar. This study is also in close agreement regarding the work-rest ratio (5.1 seconds : 9.3 seconds) observed by Coad et al. ${ }^{19}$ The corresponding lactate values also indicate that the aerobic contribution to practice performed in this way is very high and aerobic system is instrumental in delaying the increase in blood lactate values. The high percentage of maximum heart rate sustained throughout the play depicts a considerable stress on the cardiovascular system. Mean oxygen uptake observed during the game was 2.29 (0.61) minutes, which corresponds to proportionate loading of oxygen transport system $\left(57 \%\right.$ of $\left.\dot{\mathrm{V}}_{2 \text { max }}\right)$, suggesting moderate strain on aerobic mechanisms. Bartunkova et $a l^{20}$ found a mean $\dot{\mathrm{V}}_{2}$ value of $1.91 \mathrm{1} / \mathrm{min}$ in junior players, - that is $52 \%$ of $\dot{\mathrm{VO}}_{2 \text { max }}$. Mean blood lactate during match play for Indian badminton players was 4.7 (1.9) $\mathrm{mmol} / \mathrm{l}$. The highest recorded value found by Mikkelsen ${ }^{3}$ was 6.7 $\mathrm{mmol} / \mathrm{l}$. Low lactate readings may be caused by short intermittent exercise in which myoglobin can act as a short-term supplier of oxygen, particularly at the onset of activity. ${ }^{7}$ The concomitant low blood lactate concentration shows that the players exhibit a high degree of aerobic fitness. The mean average heart rate of the

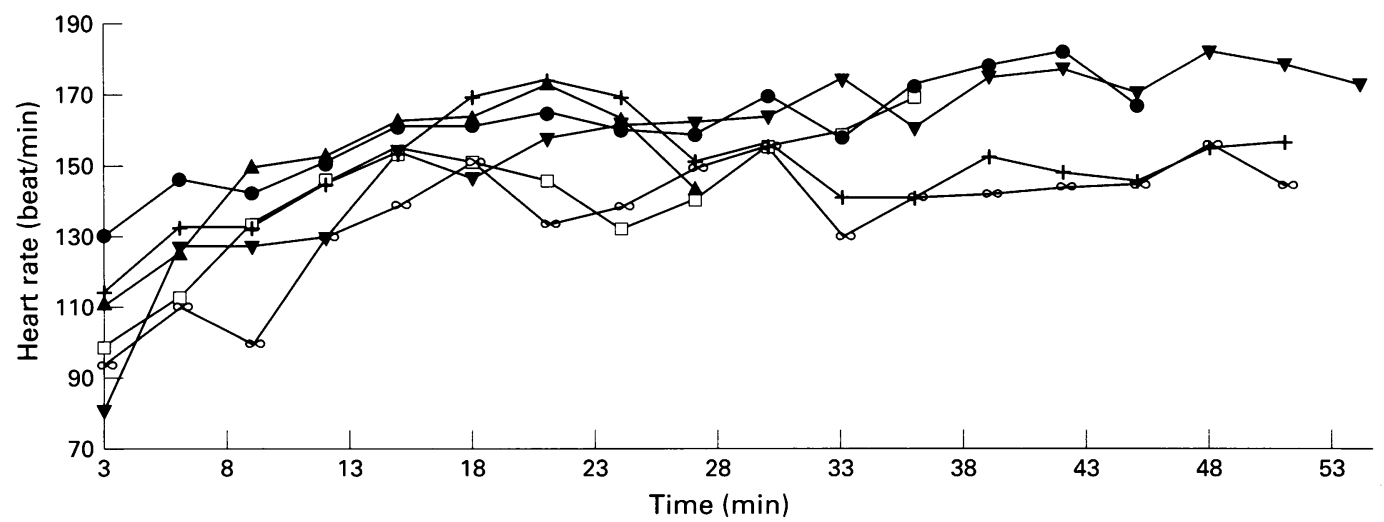

Figure 2 Heart rate response of badminton players in a game situation. 
present subject players was 157 (11) beat $/ \mathrm{min}$ (fig 2), Ritell and Waterloh ${ }^{21}$ recorded higher values 175 (6) beat $/ \mathrm{min}$, although the play monitored may have been more intense. The present percentage of maximum heart rate was $85 \%$, which is comparable to $80 \%$ of highly skilled players as reported by Docherty. ${ }^{18}$ The average heart rate of Indian players during matchplay was $85 \%$ of maximum. Reilly ${ }^{10}$ reported that the higher heart rate measured in badminton may result from the postural demands of isometric contraction in the game along with short recovery periods, which could lead to cause non-linearity of $\mathrm{HR}-\dot{\mathrm{VO}}_{2}$ relation, resulting in higher heart rate.

The high intensity work interval in on court technical training lasted for 40 to 50 seconds, a duration that is useful in overloading the glycolytic system. However, high lactate values of 8 to $10.5 \mathrm{mmol} / \mathrm{l}$ in different segments were noted in on court training. Multifeed shuttle practice with approximately one minute on: one minute off, work: rest ratio produced a blood lactate of $4.0-4.2 \mathrm{mmol} / 1$ in two players, while maxima shadow play sessions, (20 seconds on: $40 \mathrm{sec}$ onds off) increased blood lactate to $7.2 \mathrm{mmol} / \mathrm{l}^{7}$ In this study, the higher lactate response (8-10.5 $\mathrm{mmol} / \mathrm{l}$ ) in shadow play is probably because of its lower technical requirement, allowing the player to operate at a greater exercise intensity than is possible for the multifeed work.

The demand of the game does not correspond to the training system as the maximum lactate seen by several authors ranges from 3-6 mmol/ $/ .^{238}$ Intense workouts can interfere with coordination, which is very important in sports requiring high technical skill such as badminton. Some authors recommended that the training intensity may be fixed below the lactate concentration of $6 \mathrm{mmol} / 1$, because when coordination is disturbed, training could have negative effects on skills. ${ }^{22} \mathrm{High}$ lactate concentrations also inhibit fat oxidation when glycogen reserves are depleting. ${ }^{23}$ The aerobic enzyme activityin the muscle cell is reduced by acidosisthus affecting aerobic endurance. $^{2124}$ The training heart rate at various segments corresponds to actual demand, but as the duration was longer the production of lactate at various segment was high.

Urea level was increased by $11.5 \%$, this increment may be caused by the possible involvement of protein, which is directly related to the availability of substrate. There was no significant changes in packed cell volume values (before $45.9(2.5)$ and after $47.8(2.7 \%))$.

Uric acid significantly $(P<0.01)$ increased after an exhaustive workout. Increased uric acid concentrations in the period after exercise reflects the prevailing energy state. ${ }^{25}$ Excess uric acid production may lead to tissue damage because of free radicals, and may also contribute to the destruction of red cells. ${ }^{26}$ An increase in uric acid of up to $50 \%$ shows the high intensity of the training programme workout.

CPK was significantly increased by $16.3 \%$. As CPK is a large protein its presence in the blood indicates damage to the muscle cell membrane, which has been noted after intensive exercise. ${ }^{27} 28$

\section{Conclusion}

This study concludes that the heart rate-lactate response in on court training rated relatively high compared with the game situation. Biochemical values (urea, uric acid, CPK) monitored to gauge the training intensity were also significantly higher in training. It should be noted that training that is too intense may have adverse effects on coordination and hence on skill practice.

1 Agnevik G. Badminton, Indrotts Physiology Rappert no8. Stockholm: Teygg, Hansa, 1970.

2 Coad D, Rasmussen B, Mikkelson F. Physical demand of badminton. International Congress on Sports Science. Alberta,Canada:University of Alberta, 1978:106.

3 Mikkelsen F. Physical demands and muscle adaptation in elite badminton players. In: Terauds J, ed. Science in racque sports. Del Mar, CA : Academic Publishers, 1979: 55-67.

4 Gports. Del Mar, CA : Academic Pubsh Ahuja A, Khanna GL, Puri TPS. Physiological Ghosh AK, Ahuja A, Khanna GL, Puri TPS. Physiological
variables of elite Indian badminton players at anaerobic variables of elite Indian badminton players at a
threshold level. World Badminton 1987;15:169-72.

5 Ahuja A, Ghosh AK, Goswami A, Majumdar P, Khann GL, Bhandari S, et al. Specific training and its effect on GL, Bhandari S, et al. Specific training and its effect on max of ventilatory threshold of badminton players. Fakarta

coaching seminar. Jakarta: Indonesian Badminton Associ-
ation, 1989: 2-6.
6 Khanna GL, Majumdar P, Mandal, M, Saha M. Effect of six Khanna GL, Majumdar P, Mandal, M, Saha M. Effect of six weeks conditioning programme on submaximal and maximal cardiorespiratory variables in national badminton players. Indian fournal of Sports Science and Physical Education 1994;6:119-26.

7 Hughes MG. Physiological demands of training in elite badminton players. In: Reilly T, Hughes M, Lees A, eds. Science and racket sports. London: $\mathrm{E}$ and $\mathrm{F} N \mathrm{~N}$ Spon, 1995: 32-7.

8 Dias R, Ghosh AK. Physiological evaluation of specific training in badminton. In: Reilly $\mathrm{T}$, Hughes $\mathrm{M}$, Lees A, eds. Science and racket sports. London: $\mathrm{E}$ and $\mathrm{F} \mathrm{N}$ Spon, 1995 Science

9 Shephard RJ. Test of maximum oxygen intake- A critical review. Sports Med 1984;1:99-145.

10 Reilly T, Secher N, Snell P, Williams C. Physiology of sports. New York: E and F N Spon, 1990

11 Graham TE. Measurement and interpretation of lactate. In Lollegen H, Mellerowicz H, eds. Progress in ergometry, qual ity control and test criteria. New York: Springer-Verlag, 198 :51-66.

12 Bradfield RA. A technique for determination of usual daily energy expenditure in the field. Am 7 Clin Nutr 1971;24: $1148-54$

13 Christensen CC, Frey HMM, Foenstelen E, Adland E, Refsum EE. A critical evaluation of energy expenditure curve and average daily heart rate. Am f Clin Nutr 1984;37: curve and $468-72$.

14 Morgan DB, Bennett $T$. The relation between heart rate and $\mathrm{O} 2$ consumption during exercise. $\mathcal{f}$ Sports Med Phys Fitnes 1976;16:34-8.

15 Janssen PGJM. Heart rate monitoring for estimation of training intensity. In: Karvonen J, Lemon PWR, Iliev I. Medicin in sports training and coaching. Basel: Karger, 1992: 115-59.

16 Ghosh AK, Goswami A, Majumdar P, Mathur DN. Hear rate and blood lactate response in field hockey players. Indian 7 Med Res1991;(B) 94:351-6.

17 Clarke HH, Clarke DH. Advance statistics with application to physical education. New Jersey: Prentice Hall, 1974

18 Docherty DA. Comparison of heart rate response in racquet games. Br $\mathcal{F}$ Sports Med 1982;16:96-100.

19 Coad D, Rasmussen B, Mikkelsen F. Physical demands of recreational badminton. In: Terauds J, ed. Science in racquet sports. Del Mar, CA: Academic Publishers, 1979: 45-54

20 Bartunkova S, Sufarik V, Melicharova E, Bastunck A Seliger VUKF. Bures fournal Energeticky Vydaju Badminton Seliger VUKF. B
1979;27:369-72.

21 Rittell HF, Waterloh E. Radiotelemetric bei Tennis, Badminton Und Tischjennisspieler. Sportazzt Sportmedizin 1975;15:144-50.

22 Janssen PGJM. Training, lactate, pulse rate. Oulu: Liitto Oy, $1989: 42-101$

23 Power SK, Howley ET. In: Rogers C, Brown WC, eds. Exercise physiology; theory and application to fitness and performance. Dubuque: Brown, 1990; 61-7.

24 Rispens P, Lamberts K. Physiological, biomechanical and tech nical aspects of speed skating. (Dissertation). Groningen: University of Groningen, 1985 .

25 Mackinnon LT, Hooper S. Overtraining: state of the art review. Excel 1992; 8:3-12.

26 Holly RG, Barnard RJ, Rosenthal M, Applegate E, Pritikin N. Triathlete characterization and response to prolonged Triathlete characterization and response to prolonged
strenuous competition. Med Sci Sports Exerc 1986;18:123-7.

27 Janssen E, Kuipers H, Keizer H. Plasma CPK and AST activity and plasma testosterone after $200 \mathrm{Km}$ speed skatactivity and plasma testosterone after 200
ing. Med Sci Sports Exerc 1986;18:542-8.

28 Stray-Gundersen J, Videman T, Snell PG. Changes in selected objective parameters during overtraining. Med. Sci Sports Exerc 1986;18:554-5. 